\title{
Understanding Demographic Transitions: An Overview of French Historical Statistics
}

\author{
by Claude Diebolt and Faustine Perrin \\ Cham, CH: Springer, 2017 \\ Population Economics Series 18 \\ ISBN 978-3-319-44650-9 \\ Hardcover US\$129, 176 pp.
}

\section{Reviewed by John F. May}

Georgetown University

The demographic transition, which can be defined as a "logical succession of historical phases through which every population passes in the movement toward modernity" (Chesnais 1992) is a broad-based transformative process that has spread to all countries around the world since the end of the eighteenth century. France constitutes the first clear case of fertility decline in Europe, which started before the French Revolution. The French situation has been studied most notably by Etienne Van De Walle (1974) and Noël Bonneuil (1997).

In the past decades, many demographers have attempted to identify the factors causing the fertility decline - the last phase of the demographic modernization. One major endeavour was the Princeton European Fertility Project, under which Van De Walle carried out his study of the French female population in the nineteenth century. The Princeton Project, as it is known in short, was initiated in 1963 by Ansley J. Coale. The goal of this huge analytical effort was to examine the changes in childbearing and marital fertility in 700 provinces and administrative units of Europe. The work covered nearly a century of European fertility development, from 1870 until 1960. All the analyses used comparable fertility indices, which were specifically designed for the study (some of these indices are referred to in the book under review). Eleven major volumes were published under the project over twenty years, with most being devoted to a particular European country (e.g., Belgium, France, Germany, Italy, Portugal, Russia, and United Kingdom). Unfortunately, the Princeton Project did not arrive at firm conclusions as to the key factors that could explain the decline of fertility (see Coale and Watkins 1986). The project findings eventually led to the conclusion that even though economic factors played a role in the fertility decline, the economy was not the key determinant. The project also highlighted that the fertility decline did not necessarily follow the decrease of infant mortality, thus challenging somewhat the classical model of the demographic transition.

In their search for causes of the fertility decline, researchers have proposed many different explanations. Dudley Kirk, in his classic essay "Demographic Transition Theory" (1996), summarized various potential factors. He listed the decrease in mortality, improvement of socio-economic conditions, the generational reversal of wealth flows (the Caldwell hypothesis), cultural and ideational factors, lessons from history (e.g., the fertility behaviour of vanguards groups), the role of 
government and public policies, and last but not least, the role of the process of diffusion of new behaviour.

Today, we are still missing a paramount factor to explain the decline of fertility in Europe, and this volume by Diebolt and Perrin is therefore a most welcome addition to the ongoing research. Because many unresolved questions still hamper the search for causality of the French fertility decline, the goal of the research by Diebolt and Perrin is to better understand the reasons for the changing patterns of demographic behaviour. In their analysis, they investigate the female labour force, educational investments, and gender relations as other key factors that may explain the fertility decline, or at least contribute to a better understanding of the broader socio-economic context in which the fertility decline occurred. Their book, which covers a very large time span, i.e., the past 200 years, analyzes the demographic transition in France from two original angles: (1) the broad array of explanatory factors being investigated; and (2) the variety of historical sources and statistics used to carry out the research at hand.

The book is organized into four major chapters. First, the volume reviews the evolution of demographic behaviour. This chapter describes the different phases of the demographic transition, including the evolution of mortality and fertility levels as well as the natural balance between these two components. Thereafter, the chapter analyzes the changing demographic behaviour (i.e., marriage patterns and birth limitation) and the transformation of the French demographic landscape, with a focus on fertility rates' geographical variations.

The second chapter examines changes in the labour force. In particular, it describes the evolution of the female labour force, the life cycle labour force participation, and the French labour force's regional dynamics, focusing on the gender gap in labour force participation, earnings, and occupations.

The third chapter explains the increasing investment in female educational in France. It describes the evolution of the female human capital, including the literacy rates, the expansion of schooling, and educational investments and aspirations. Thereafter, the chapter focuses on regional discrepancies in schooling, covering literacy rates, enrollment rates, and the distribution of infrastructure. Finally, this section of the book analyzes the schooling gender gap on a regional basis.

Finally, the fourth and last chapter examines the transformation of gender relations through the lens of female empowerment. The chapter distinguishes the "traditional" role of women from an emerging new socio-economic role for women, and the more recent "quiet revolution." Last but not least, the chapter examines regional dynamics of the gender gap and related changes in socio-economic status.

Overall, the first chapter of this book provides a solid basis for the three subsequent chapters. Nonetheless, despite the extensive analyses being offered (including a detailed discussion of causality between fertility and the system of inheritance; see p. 30-31), the chapter concludes that it is not possible to provide explanations for the demographic mutations that occurred in the nineteenth century without also understanding the social and economic changes that took place in France during the last two centuries.

Therefore, the volume embarks subsequently on a detailed analysis of the labour force, educational investments, and gender relations. In doing so, the authors depart from the classic analysis of fertility evolution, which is based essentially on demographic data gathered from traditional population sources (e.g., censuses). Instead, the authors shift their focus to socio-economic factors, using in the process an array of new data that remain usually outside the purview of demographers, although these data may also come from traditional population sources. In particular, the authors use the Statistique de la France, a rich corpus which they mine extensively. They also rely on agricultural and educational statistics. 
The increased participation of women in the labour force cannot be explained without the factor of improved female education investments and outcomes. Moreover, developments in female labour force participation and enhanced educational achievements among girls have occurred in tandem with improved gender relations, through which women have been able to assert their role more forcefully. As a result, the decline of fertility, which was so far understood essentially as a demographic process, is now described in the broader context of major socio-economic changes. For instance, it is important to understand the shift from urbanization to industrialization and, eventually, "tertiarization." The authors conclude that the decline of fertility in France is explained much more satisfactorily by considering changes in the three areas of labour force, educational achievements, and evolving gender roles.

The analysis presented in the book was conducted mainly at the level of the département, a term (poorly) translated in the book as county or district. The reader is sometimes frustrated because many of the graphs and figures are too small to be easily legible, and would also require clearer indications on the units and/or legends being used. The book would also benefit from an extensive list of acronyms. Finally, it would have been nice to provide the full sources of the thought-provoking citations at the beginning of each chapter. However, these are very minor remarks.

As mentioned, it is the combination of the broad scope of the research being offered and the use of traditional "population" sources to gather socio-economic data, as well as of additional historical statistics, that makes this volume such an original contribution. Overall, this fine volume will not only strengthen our knowledge of the French demographic transition and its accompanying socio-economic processes, but will also, in the authors' concluding words, encourage other researchers to refine the "critiques and methods required for the good use of old statistics and to which economists, historians, and social scientists in general today are not accustomed" (p. 176).

\section{References}

Bonneuil, N. 1997. Transformation of the French Demographic Landscape 1806-1906. Oxford (UK): Clarendon Press.

Chesnais, J-C. 1992. The Demographic Transition: Stages, Patterns, and Economic Implications. Oxford (UK): Clarendon Press.

Coale, A.J., and S.C. Watkins (eds). 1986. The Decline of Fertility in Europe: Revised Proceedings of a Conference on the Princeton European Fertility Project. Princeton, NJ: Princeton University Press.

Kirk, D. 1996. Demographic transition theory. Population Studies 50(3):361-87.

Van de Walle, E. 1974. The Female Population of France in the Nineteenth Century: A Reconstruction of 82 Départements. Princeton, NJ: Princeton University Press. 